\title{
A Comparative Study of Reading Strategies Used by Chinese English Majors
}

\author{
Xiaoqiong Zhou ${ }^{1} \&$ Yonggang Zhao ${ }^{2}$ \\ ${ }^{1}$ Personnel Department, China West Normal University, Nanchong, Sichuan, China \\ ${ }^{2}$ School of foreign languages, China West Normal University, Nanchong, Sichuan, China \\ Correspondence: Xiaoqiong Zhou, Personnel Department, China West Normal University, No. 1 Shi Da Road, \\ Nanchong, 637009, Sichuan, China. Tel: 86-817-256-8025. E-mail: zhyg007@163.com
}

Received: December 16, 2013 Accepted: January 18, 2014 Online Published: February 12, 2014

doi:10.5539/elt.v7n3p13 URL: http://dx.doi.org/10.5539/elt.v7n3p13

The research is financed by Education Development Research Center of Sichuan Province (Project No.CJF13061).

\begin{abstract}
In this thesis, by means of questionnaire, we made an investigation into the reading strategies used by Chinese first-year and third-year English majors. The purpose of this study attempts to identify the typical types of reading strategies among English majors in a normal university of China, and also, to examine what differences exist in strategy use by first-year and third-year students. The output shows all the three reading strategies, whether metacognitive, cognitive or social/affective strategies are widely used by English majors in normal university. Nevertheless, differences do exist in the degree of popularity of some specific reading strategy items. The difference in use of reading strategies between first-year and third-year students is that the former are reported to employ much more social/affective strategies while the latter do much better in metacognitive and cognitive strategies. From what discussed, we know that readers can benefit a lot from appropriate reading strategies in reading, so it is possible and necessary for teachers to offer reading strategy instruction for the students and also different strategy instruction should be offered to students in different grades.
\end{abstract}

Keywords: reading strategies, comparative analysis, differences, implications

\section{Introduction}

Reading has generally held an important place in foreign and second language learning and teaching. It not only provides important and sufficient linguistic input for second language learners, but also lays a foundation for their further development in listening, speaking, writing and translating. The Teaching Syllabus for English Majors (2000) prioritizes the development of reading skills as one of the most important aspects in teaching. And also, reading occupies a large portion in most English tests. However, in practical learning and teaching, reading has been seen a hard nut to crack all along time. It has been observed that in China many EFL (English as a Foreign Language) learners are unable to read effectively, and frequently fail to comprehend texts. Students often complain they spend much time and energy in reading but with little progress. Most teachers have attributed their students' poor reading ability to linguistic deficiencies. Consequently, they encourage low-proficiency students to expand their vocabularies so as to improve their reading comprehension. Nevertheless, the result is still not optimal.

In addition, as we know, English majors' English readings have their own characteristics and advantages. Generally speaking, most of high school graduates who have been admitted to English majors, have quite solid English foundation, or at least have strong interests in it. When they entered university, differences in English reading abilities are not too obvious in the early stages. After entering the senior, however, this situation is quickly broken - a sharp differentiation appears: Some students soon surpass the others. Why does appear this kind of circumstance?

Because of all the above, we presume that reading comprehension is affected much by reading strategy use. Based on the assumption, this thesis attempts to do some research in students' reading strategies, in particular, it investigates the reading strategies of Chinese first-year and third-year college English majors. 


\section{Literature Review}

Since the early 1970s, many researchers have centered on teaching all kinds of reading strategies to second language learners in order to promote their language study in western countries. However, reference shows that reading strategy research is only becoming popular in the 1980s (Weir \& Urquhart, 1988). Generally speaking, researchers have focused on the following three aspects.

\subsection{Reading Strategies of Successful and Unsuccessful Learners}

In a research of second language learning, Honsenfeld (1977) found great differences in some reading strategies used by successful and unsuccessful readers by using a think-aloud procedure. Research shows that successful readers were good at remembering what they were reading in the process of reading, ignoring less important contents and having a positive self-sense. On the contrary, the unsuccessful were more forgetful, often interfered by redundant information in passage and had a negative self-sense. Block (1986) also used a think-aloud procedure in his investigation into two groups of non-proficient readers: integrators and non-integrators. The output shows that the former made more progress in developing their reading skills than the latter. In addition, other researchers (e.g., Alderson, 1991; Barnett, 1988; Block, 1986) have also revealed how strategic readers interact with a written text and how their strategic behaviors are related to effective reading comprehension.

\subsection{Strategy Use and Individual Differences}

Some researchers have attempted to compare the differences of strategies use between ESL readers and English natives (Cziko 1978, 1980; Kight et al., 1985, etc). Take Kight et al's for example, their study aimed to find out whether differences exist in both the type and frequency of cognitive strategies reported by the two kinds of readers. It was found some strategies such as imaging, noting details and predicting outcomes hadn't been cited by ESL students and natives used more strategies than ESL students. Another scholar, Anderson (1991) examined the differences in strategy use by some adult second language learners. Although his results show that both high and low-proficiency readers appeared to be using the same kinds of strategies while answering the comprehension question, it seemed that the former were applying strategies more effectively and appropriately. His study also indicates that both knowing which strategies to use and how to apply strategies are important in reading.

\subsection{General Reading Strategies}

Although individual differences do exist in reading strategies use, researchers argue that there are a series of general strategies to us in dealing with various texts in different circumstances. Oxford (1990) offers a useful and comprehensive classification schema of the various strategies used by learners. He divided reading strategies into six sub-strategies: cognitive strategies, memory strategies, compensation strategies, metacognitve strategies, affective Strategies and social Strategies. Based on the work of Hosenfeld (1984) and Hosenfeld et al. (1981), Cohen also lists 10 subcategories: classification of purpose, organization of text, reading for meaning, focusing on major content, parsimonious use of a dictionary, judicious use of contest, ongoing summaries, making predictions, seeking for markers of cohesion and strategies for managing strategies.

Although the above classifications can facilitate our current research, a more detailed and systematic strategy taxonomy is still needed. O'Malley and Chamot (1990) have differentiated strategies into three categories: cognitive, metacognitive and social/affective strategies. Their classification seems more detailed and systematic and one basic classification scheme by them will be adopted after a suitable adjustment in our study.

\section{Design of the Research}

\subsection{Research Purposes and Questions}

This study aims at investigating the reading strategies employed by Chinese English majors, giving a comparison of reading strategies between first-year and third-year English majors. Generally speaking, the purposes of this study are as follows: Firstly, to identify the typical types of reading strategies among English majors in a normal university; Secondly, to examine what differences exist in strategy use by first-year and third-year students. The specific questions will be given in this study as follows:

Are those reading strategies proposed according to our study on certain theories common to English majors in Chinese context? And how often do they use them?

What are the differences among the reading strategies used by first-year and third-year English majors?

\subsection{Subjects}

Altogether 170 students are involved in the investigation. All of them came from English department of 
China-west Normal University. It is the first semester of English study for the first-year students, 80persons, and fifth semester for the third-year students, 90persons. For the comparison of reading strategies, we just choose the first-year students and third-year students. The reason is that the second-year students are at a transitional stage. Their strategies may not be representative. In addition, the fourth-year students have not been involved because they are busy at job hunting. What is more, they have no formal reading class, so data collection from them may be difficult.

\subsection{Instrument}

The data for this study were from O'Malley and Chamot's proposed strategies after a suitable adjustment (1990). All the strategies are divided into three categories: cognitive, metacognitive and social/affective strategies. Cognitive strategies are specified as learning steps that learners take to transform new material. Metacognitive strategies involve consciously directing one's own efforts into the learning tasks. Social/affective strategies involve interaction with another person or taking control of one's own feelings in language learning. With the help of some teachers and classmates, a questionnaire was formed and given to subjects and all these strategies were embodied in 30 items. The questionnaire aimed to investigate the students' way of reading and their evaluation of the reading strategies from the perspective of metacognitive, cognitive and social/affective factors. In the present study, a five-point Scale is attached to each item ranging from 1 ("never or almost never true of me" to 5 "always or almost true of me". Students are asked to indicate the frequency with which they use a reading strategy implied in the statement by selecting the number that represents their response. The higher number indicates a more frequent use of the strategy concerned.

The participants were asked to respond anonymously so that there was no danger for the subjects to be individually identified. In order to avoid comprehension problems, the questionnaire is also translated into Chinese. In addition, a questionnaire was also administered to document grade and other information.

\subsection{Procedures}

In order to get a rough idea about the amount of time the whole study takes the students to complete the questionnaire and get some feedback from the subjects involved in the study, we did a pilot study in October 2010. After some further modifications based on it, a more satisfactory questionnaire came out and the actual study was carried out in December. The actual questionnaire was administered during normal class time with the help of classroom instructors. The teachers spend five minutes explaining the questionnaire such as the objective of this research and the true meaning of the numbers and so on. Then 25 minutes were given to the students to finish the questionnaire, which is sufficient. After that, the papers were gathered immediately and coded for analysis.

\subsection{Data Analysis Methods}

The Statistical Package for Social Science (SPSS Software Version 12.0) was applied in our study. First of all, the descriptive analysis was conducted to see the overall strategy use. Then the descriptive analysis and t-test were undertaken to analyze the related research question.

\section{Data Analysis}

To examine whether differences exist among the reading strategy use by first-year and third-year English majors, both means computation and T-test will be applied to treat these data. The participants include 80 first-year students and 90 third-year students.

Table 1. Use frequency and t-test of RS used by first-and third-year students

\begin{tabular}{|c|c|c|c|c|c|c|}
\hline Variables & GRADE & $\mathrm{N}$ & Mean & Std. Deviation & $\mathrm{T}$ & Sig. (2-tailed) \\
\hline \multirow{2}{*}{$\mathrm{MC}$} & G1 & 80 & 3.4409 & .32969 & \multirow{2}{*}{-2.358} & \multirow{2}{*}{.021} \\
\hline & G3 & 90 & 3.5882 & .43443 & & \\
\hline \multirow{2}{*}{ CG } & G1 & 80 & 3.0397 & .36592 & \multirow{2}{*}{-2.042} & \multirow{2}{*}{.041} \\
\hline & G3 & 90 & 3.1617 & .38097 & & \\
\hline \multirow{2}{*}{$\mathrm{AF}$} & G1 & 80 & 3.3875 & .34036 & \multirow{2}{*}{1.583} & \multirow{2}{*}{.116} \\
\hline & G3 & 90 & 3.2873 & .43173 & & \\
\hline
\end{tabular}

Note: $\mathrm{MC}=$ Metacognitive Strategy, $\mathrm{CG}=$ Cognitive Strategy, $\mathrm{AF}=\mathrm{Affective}$ Strategy. 
The data show that If we view the mean score from another perspective, we can find the mean scores on each category of reading strategies for both group are above 2.5 , above the medium level, which prove reading strategy is widely used in reading tasks by the subjects. To be more specific, the highest score goes to metacognitive. An inference can be made that the students tend to be aware of all the three major types of strategies with more emphasis on indirect way of dealing with the text. The high frequency of metacognitive strategy use may be accounted for the pressure given by examination system. Many schools in China still regard the examination scores as the best way of evaluating students. To deal with all kinds of examinations, the students have to be overwhelmed by too much new knowledge, so they must learn to plan, monitor, and evaluate their learning. Therefore, reflected in reading tasks, they show much stronger abilities in making use of metacognitive strategies.

However, differences do appear. To be more exact, the third-year students do better on metacognitive strategy use $(M=3.5882)$ and cognitive strategy use $(M=3.1617)$ than the first-year students $(\mathrm{Mm}=3.4409 ; \mathrm{Mc}=3.0397)$. Maybe it attributes the reason that the third-year students get more reading strategies practice at college. Nevertheless, the first-year students out-performed on social/affective strategy $(M=3.3875)$ than the third-year students $(\mathrm{M}=3.2873)$. The reasons maybe lie in that (1) First-year students are willing to ask for help or cooperate with others when encountering difficulties in reading while third-year students are more inclined to solve problems by themselves. (2) With regard to motivation, the first-year students have comparatively higher motivation because they may consider the university as an ideal place of further study. However, some third-year students may be demotivated as the college life goes on. For one thing, some less successful learners have lost heart in studies; for another, some students are lacks of further motivation to study after passing TEM4.

Besides, making use of descriptive analysis and t-test, we also find that there are significant differences between the former two categories of strategy use: metacognitive strategy use $(t=-2.358, p<0.05)$, cognitive strategy use $(\mathrm{t}=-2.042, \mathrm{p}<0.05)$ and significant differences do not exist between affective/social strategy use.

Table 2. The use frequency of each item and output of t-value

\begin{tabular}{|c|c|c|c|c|c|}
\hline Variables & $\mathrm{t}$ & Sig. & Variables & $\mathrm{t}$ & Sig. \\
\hline I read attentively in any situations. & -2.293 & .025 & $\begin{array}{l}\text { I take the reading course for } \\
\text { the need of my future career. }\end{array}$ & .852 & .397 \\
\hline I'm clear of my reading purpose. & -2.157 & .035 & $\begin{array}{l}\text { I read in English for passing } \\
\text { exams or getting certificates. }\end{array}$ & 2.409 & .043 \\
\hline $\begin{array}{l}\text { The materials which I read from } \\
\text { textbooks. }\end{array}$ & .557 & .579 & $\begin{array}{l}\text { I read in English for learning } \\
\text { more about English culture. }\end{array}$ & -2.134 & .035 \\
\hline $\begin{array}{l}\text { I read other materials given by the } \\
\text { teacher. }\end{array}$ & -.386 & .702 & $\begin{array}{l}\text { I give myself a reward when I } \\
\text { do well in English reading. }\end{array}$ & .419 & .675 \\
\hline $\begin{array}{l}\text { I read English magazines, } \\
\text { newspapers and novel. }\end{array}$ & -2.507 & .015 & $\begin{array}{l}\text { I look an unfamiliar word up } \\
\text { in a dictionary. }\end{array}$ & .125 & .901 \\
\hline $\begin{array}{l}\text { I think intensive reading is very } \\
\text { important. }\end{array}$ & .457 & .649 & $\begin{array}{l}\text { I try to guess the meanings } \\
\text { from context. }\end{array}$ & -2.358 & .021 \\
\hline $\begin{array}{l}\text { I think extensive reading is very } \\
\text { important }\end{array}$ & -.029 & .978 & $\begin{array}{l}\text { I neglect an unfamiliar word } \\
\text { and continue my reading. }\end{array}$ & -2.293 & .022 \\
\hline I improve my way of reading. & -.937 & .351 & $\begin{array}{l}\text { I look for cohesive ties: this, } \\
\text { that, here, there and so on. }\end{array}$ & -.1285 & .202 \\
\hline $\begin{array}{l}\text { I enlarge vocabularies and expand } \\
\text { other knowledge. }\end{array}$ & -2.573 & .012 & $\begin{array}{l}\text { After getting a general idea, } \\
\text { then I read materials slowly. }\end{array}$ & -.780 & .437 \\
\hline $\begin{array}{l}\text { Associate text information with } \\
\text { related materials. }\end{array}$ & -.226 & .823 & $\begin{array}{l}\text { I read a text with questions to } \\
\text { look for answers. }\end{array}$ & -2.622 & .011 \\
\hline $\begin{array}{l}\text { I reread to understand the confusing } \\
\text { part. }\end{array}$ & -.196 & .845 & $\begin{array}{c}\text { To get a general idea of a text, } \\
\text { I read its title. }\end{array}$ & -.319 & .751 \\
\hline $\begin{array}{l}\text { I am always confident while } \\
\text { reading. }\end{array}$ & 1.839 & .067 & $\begin{array}{l}\text { Before reading, I predict what } \\
\text { the author will say. }\end{array}$ & -1.361 & .176 \\
\hline $\begin{array}{l}\text { In reading, I do not feel anxious and } \\
\text { relax myself. }\end{array}$ & .483 & .630 & $\begin{array}{l}\text { I translate sentences into } \\
\text { Chinese for understanding. }\end{array}$ & -2.003 & .046 \\
\hline $\begin{array}{l}\text { Meeting difficulties, I ask the others } \\
\text { for help. }\end{array}$ & 2.281 & .025 & $\begin{array}{l}\text { I will vary my reading speed } \\
\text { from time to time. }\end{array}$ & -.057 & .954 \\
\hline $\begin{array}{l}\text { I manage to overcome difficulties in } \\
\text { reading. }\end{array}$ & -.822 & .413 & $\begin{array}{l}\text { In order to understand better, I } \\
\text { read word by word. }\end{array}$ & -.383 & .702 \\
\hline
\end{tabular}


The above table consists of 30 items from metacognitive strategy, cognitive strategy and affective strategy separately. The output shows differences of reading strategies do exist, even significant differences in some items between two grades which correspond to the output of table1. The latter list as follows:

1) I read attentively in any situations, even in a noisy one.

2) I'm clear of my reading purpose.

3) The materials which I read are English newspapers, magazines, and novel and so on.

4) In order to improve reading ability, I enlarge vocabularies and expand other ranges of knowledge.

5) When I encounter difficulties in reading, I ask the teacher or classmates for help.

6) I read in English in order that I can pass the English exams or get certificates.

7) I read in English in order that I can learn more about English culture and custom.

8) When I encounter an unfamiliar word, I try to guess the meanings from context.

9) With certain comprehension questions in mind, I read a text quickly to look for the answers.

10) I translate some sentences into Chinese for better understanding in my reading.

11) I Continue to read without interruption when meeting with difficulty.

We have mentioned that the third-year students are better at metalcognitive strategies because of their systematic strategies practice. Therefore they have much stronger abilities of monitoring (a \& b). First-year students have been just admitted into college and their first-year study in college is an important transitional stage from high school learning style to university style. Being affected by exam-oriented education, they have strong instrumental motivation, "reading in English in order to pass the English exams or get certifications" (f). At the same time, in order to improve reading ability, they depend on "enlarge vocabularies and expand other ranges of knowledge" (d). In addition, because of low-level reading abilities, they are eager to ask for help or cooperate with others when meeting with difficulties in reading. As a result, they significantly apply strategies such as "ask the teacher or classmates for help" (e), and "translating some sentences into Chinese in reading" (j). On the other hand, after passing TEM4, many third-year students have turned their instrumental motivation into integrated motivation and desire to achieve proficiency in English in order to know more about the other culture, and participate in the life of the community of the native speakers (g). They have been accustomed to college learning, formed their own learning styles and also their reading abilities are improved after formal strategy instruction. As for improvements of reading abilities, firstly, they have the abilities to read more authentic reading materials. As shown in Table2, they present significant differences in using strategies such as "choosing English newspapers, magazines, novels and so on as reading materials"(c); Secondly, they show stronger abilities in monitoring mistakes. "Continuing to read without interruption when meeting with difficulty" reveals their abilities of repairing comprehension failures in reading $(\mathrm{k})$; Thirdly, they show strong tendency to use higher-level skills such as "guessing" (h). Since "scanning" is a strategy proposed and explicitly instructed in the extensive reading course from the second year of their study, it is not surprising the third-year students are more adept at it (i). This is also shows the necessity of reading strategy instruction.

In summary, the result of different strategy preference of first- and third-year students derives from a direct result of strategy instruction.

\section{Conclusion}

Reading strategy belongs to the one of readers' individual variables, which is easier to get changed than the other ones. Besides, from what discussed, we know that readers can benefit a lot from appropriate reading strategies in reading, so it is possible and necessary for teachers to offer reading strategy instruction for the students. Our study shows that different strategies are adopted by students from different grades. The difference in use of reading strategies between first-year and third-year English majors is that the former are reported to employ much more social/affective strategies while the latter do much better in metacognitive and cognitive strategies. We should attach much importance to the difference.

This study has certain enlightenment to our reading teaching. Firstly, differences of different grades in reading strategy use requires teachers of different types of teaching methods; Secondly, junior students' bad reading habits bringing from high school, such as excessive reliance on help or mother tongue, etc., should be corrected in order to adapt to college study; Thirdly, reading skills should be taught in systematic way in teaching reading; Besides, with the increase of students' language level, different reading strategies should get corresponding practice; Furthermore, students' learning motivation should be strengthened; At last, For the strategies used by 
the above two grades obviously different, we should give an introduction as soon as possible, inspire and guide students to use them widely in practical reading.

\section{References}

Anderson, N. J. (1991). Individual differences in strategies use in second language reading and testing. The Modern Language Journal, 75(4), 411-541. http://dx.doi.org/10.1111/j.1540-4781.1991.tb05384.x/abstract

Barnett, M. (1988). Reading through context: How real and perceived strategy use affects 12 comprehension. The Modern Language Journal, 72, 150-162. http://dx.doi.org/10.1111/j.1540-4781.1988.tb04177.x

Block, E. (1986). The comprehension strategies of second language readers. TESOL Quarterly, 20(3), 463-494. http://dx.doi.org/10.2307/3586295

Cziko, G. A. (1978). Differences in first and second language reading: The use of syntactic, semantic and discourse constraints. Canadian Modern Language Review, 34, 473-489.

Cziko, G. A. (1980). Language competence and reading strategies: A comparison of first and second language oral reading errors. Language learning, 30, 101-114. http://dx.doi.org/10.1111/j.1467-1770.1980.tb00153.x/abstract

Hosenfeld, C. (1977). A preliminary investigation of the reading strategies of successful and nonsuccessful second language learners. System, 5, 110-123. http://dx.doi.org/10.1016/0346-251X(77)90087-2

Hosenfeld, C., Arnold, V., Kirchofer, J., Laciura, J., \& Wilson, L. (1981). Second language reading: A curricular sequence for teaching reading strategies. Foreign Language, 14(5), 110-123. http://dx.doi.org/10.1111/j.1944-9720.1981.tb01661.x

Hosenfeld, C. (1984). Case studies of ninth grade readers. In J. C. Aderson, \& A. H. Urquhart (Eds.), Reading in a foreign language New York (pp. 231-249). London: Loman.

Kight, S. L., Padron, Y. N., \& Waxman, H. C. (1985). The cognitive reading strategies of ESL students. TESOL Quarterly, 19(3), 789-792.

Olshavsky, J. E. (1977). Reading as a problem solving: An investigation of strategies. Reading Research Quarterly, 12, 654-674. http://dx.doi.org/10.2307/747446

O’Malley, J. M., \& Chamot, A. U. (1990). Learning strategies in second language acqusition. Cambridge University Press.

Oxford, R. L. (1990). Language learning strategies: Whatever teachers should know. New York: Newbury House Publishers.

Weir, C. J., \& Urquart, A. H. (1988). Reading in a second language: Process, Product and Practice. London: Longman.

Wang, L. F., \& Wen, Q. F. (2003). English Learning Strategies for Training and Research in China. Foreign Language World, 6, 49-54. $\quad$ Retrieved http://www.cnki.net/KCMS/detail/detail.aspx?QueryID=4\&CurRec=2\&recid=\&filename=WYJY20030600 $8 \&$ dbname $=$ CJFDHIS $\&$ dbcode $=$ CJFQ \&pr $=\& u r l i=\& y x=\& u i d=$ WEEvREcwSIJHSldSdnQ1 Yk9kUUlFRndh NnVSQ0RHZmhMYjZqaVhLL0NqQ0IvMnlXZlAwcDRQc1I5cGJubXhJPQ==\&v=MjIyOTZyV00xRnJD VVJMbWVaZVptRkNqaFVML01NalRCZDdHNEh0TE1xWTIGYk1SOGVYMUx1eFITN0RoMVQzcVQ $=$

Teaching Syllabus for English Majors. (2000). Shanghai: Shanghai Foreign Language Education Press.

\section{Copyrights}

Copyright for this article is retained by the author(s), with first publication rights granted to the journal.

This is an open-access article distributed under the terms and conditions of the Creative Commons Attribution license (http://creativecommons.org/licenses/by/3.0/). 